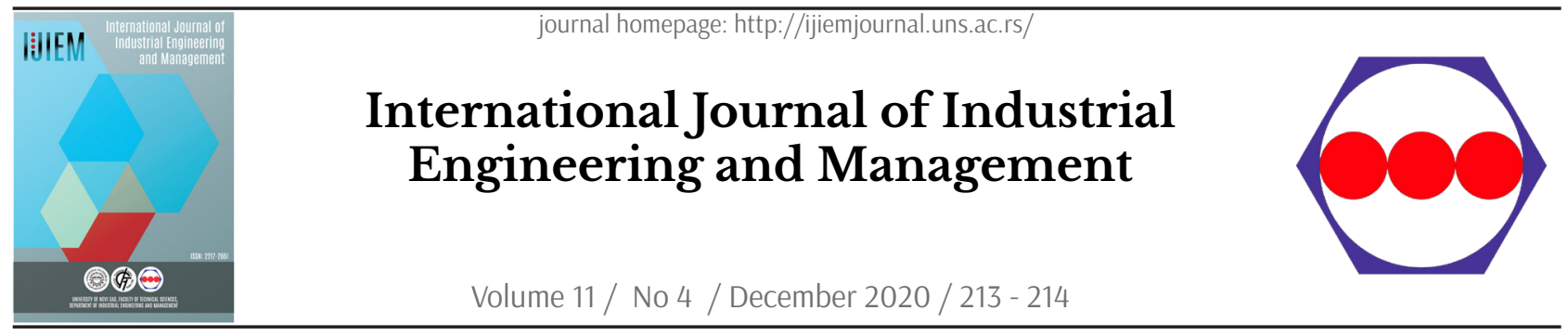

Editorial

\title{
EDITORIAL: \\ The path towards the Web of Science
}

Ugljesa Marjanovic

\author{
Editor-in-Chief, International Journal of \\ Industrial Engineering and Management \\ Professor of Industrial Engineering and Management \\ University of Novi Sad, \\ Faculty of Technical Sciences, \\ Novi Sad, Serbia \\ umarjano@uns.ac.rs
}

On October 21, 2020, the IJIEM journal has reached a milestone - an application for the IJIEM journal's evaluation was submitted to the Web of Science Core Collection. After more than ten years since its foundation [1] and service to its readership, the IJIEM journal decided to expand the potential for the network of citations within Engineering, Industrial scientific discipline of Web of Science. We hope to receive valuable support and contribution in this endeavor from our authors, Editorial Board members, reviewers, and readers.

In this editorial, I present the papers of Volume 11, Issue 4.

We published 24 articles in Volume 11, six papers in each of the four issues..

\section{The aim and structure of this Issue}

This Issue contains six articles covering topics from electric vehicle routing problems, online shopping challenges, lean manufacturing, project management, application of VR and AR, and cumulative capability development models.

The article Electric Vehicle Routing Problem with Heterogeneous Vehicles and Partial Charge by H. Park and S. Jin presents a mathematical formulation to solve an electric vehicle routing problem with heterogeneous vehicles and partial charge total distance traveled by the vehicles. The authors conducted a numerical analysis to validate the proposed model and demonstrate its practical applicability.

W. Widyastuti, S. Hartini, and Y. Artanti published the paper Revisiting the online shopper's behavior in Indonesia: The role of trust and perceived benefit. In their study, the authors analyzed the factors that influence 
attitudes toward online shopping in Indonesia. Authors revealed that high levels of trust influence consumer attitudes toward online shopping, while at low levels of trust, consumer attitudes will be more influenced by perceived benefits.

How to solve the increasing quality problems of a small drones' assembly company are discussed and illustrated in the article UAVs' efficient assembly: Lean Manufacturing implementation in an UAVs' Assembly Company. S. A. Villacís and P. S. Burneo used a circular DMAIC methodology, line balancing, and simulation to demonstrate a reduction of the lead time and an increment in the leanness degree level.

In the article Application of system dynamics in the assessment of project portfolio performance, S. A. Zarghami and J. Dumrak introduced the System Dynamics modeling approach to create a link between a portfolio and its constituent projects. The proposed model revealed that shifting priorities due to the lack of organizational factors result in the delay and cost overrun in projects, thereby decelerating the improvement in the projects' status within a portfolio.

The next paper by J. Duda and S. Oleszek Realization of PLM application integration with AR technology presents a proposal for a technical procedure for implementing the integration of a commercial PLM and a proprietary AR system.

Finally, the paper The cumulative capability models: A contingency analysis by M. Vilkas, J. Duobiene, R. Rauleckas investigates the impact of internal organizational factors in contrasting capability development sequences. The paper suggests that strategic priority is a vital contingency factor for explaining whether an organization will follow the sand cone sequence of capability development.

\section{References}

[1] U. Marjanovic, "The IJIEM as a platform for engagement," Int. J. Ind. Eng. Manag., vol. 11, no. 2, pp. 71-72, 2020. DOI: 10.24867/IJIEM-2020-2-editorial. 